\title{
SPATIAL TRANSIT ACCESSIBILITY MODELING OF INDIAN METROPOLITAN CITY IN GIS ENVIRONMENT
}

\author{
Manjurali Imadadali Balya ${ }^{1}$, Bhimaji Krishnaji Katti ${ }^{2}$, Krishna Saw ${ }^{3}$ \\ 1,2,3 Sardar Vallabhbhai National Institute of Technology, Surat, India
}

Received 23 January 2015; accepted 12 February 2016

\begin{abstract}
With increase in city size and population in developing country like India, the travel demand is increasing very fast which calls for an efficient and effective transit to fulfill the demand of travelling public. The transit accessibility is one of the most alarming factors of the increased urbanized areas of these cities. The case study presented the spatial transit accessibility index modeling with due consideration factors viz. walking distance and walking time of the study area. The spatial accessibility is measured on the basis of home interview data and as well on GIS base to develop "Accessibility Catchments" through buffering process for different accessibility scales of radius of $250 \mathrm{~m}, 350 \mathrm{~m}$ etc. The catchment areas marked provide the scope to identify "Accessibility Thirst Areas". The research work further addresses the development of proposed LOS for both distance and time units. The transit accessibility index modeling and proposed LOS of the present study shows the promising results and can apply to the same sized urban cities. These findings presented in the paper are case specific and can be apply as a base for finding the spatial accessibility status for metropolitan cities.
\end{abstract}

Keywords: public transportation, Spatial Transit Accessibility Index (STAI), Geographical Information System (GIS), Level of Service (LOS).

\section{Introduction}

With increase in city size and population in developing country like India, the travel demand is increasing very fast which calls for an efficient and effective transit to fulfill the demand of travelling public. The operational planning of the bus system, quality of service are the major factors deciding the ridership levels for the given demand profile. However effective and efficient public transport system, it is quite essential to understand the accessibility status. Accessibility is concerned with the opportunity that an individual at a given location possesses to participate in a particular activity or set of activities. Accessibility is defined by U.S. Department of Environment (1996) as "the ease and convenience of access to spatially distributed opportunities with a choice of travel." Accessibility depends on the transportation, temporal (time), and spatial location constraints which limits the ability of individuals to participate in productive activities (Odoki et al., 2001). Accessibility measurement is one of the critical factors of the present urbanized cities. Present research study has focused on the spatial accessibility of the public transport.

Being the first points of contact between the passenger and the transit service, access

${ }^{1}$ Corresponding author: mibalya.civil@spcevng.ac.in 
to public transport stops is an important factor affecting overall transit trip travel time (Foda and Osman, 2010). Many studies on public transport have shown that walking is the most natural and important mode to access public transport (Cervero, 2001; Loutzenheiser, 1997; Mitchell and Stokes, 1982; Stringham, 1982). In planning for the provision of bus-based transit service, accessing a bus stop is considered to be achieved mainly by walking (Foda and Osman, 2010).

Walking accessibility to public transport is applied to indicate the quality or performance of public transport service (Polzin et al., 2000; Rudnicki, 1999). Based on an assumed average walking speed of about $1.3 \mathrm{~m} / \mathrm{s}, 5$ minutes of walking is considered reasonable in urban areas, which are about 400 meters in terms of walking distance (Levinson, 1992; Foda and Osman, 2010). Over the past decade, many researchers have turned to geographical information systems (GIS) technology for accessibility analysis (Arentze et al., 1994; Geertman and Ritsema Van Eck, 1995; Gutiérrez et al., 1998; Juliao, 1999; Kwan, 1998; O’Sullivan et al., 2000; O'Sullivan and Morrall, 1996; Shen, 1998; Van Eck and De Jong, 1999). The indexes of accessibility that describe the correlation between land use patterns and transportation systems have been used extensively by researchers and policy makers, especially in assessing the existing transportation system and forecasting its performance (Dong et al., 2006).

Present study mainly describes the spatial accessibility which is measured on the basis of home interview data and as well on GIS base to develop Accessibility Catchments through buffering process. The structure of the paper is as follows. The next section briefly reviews the previous literatures studies. A section describing the database follows it. Development of Transit Accessibility Index (TAI) and transit preference analysis are presented in the section after that. Modeling of transit accessibility with its results and GIS Software base with its impact are described in the next section. Proposed LOS of the transit accessibilities for the study areas are mentioned in the second last section. Key conclusions are presented in the last section.

\section{Literature Background}

\subsection{Accessibility Concept}

Accessibility is often defined as the ease of travel between two locations. Oxford Advanced Learner's Dictionary (2000) defines 'accessible' as "that can be reached, entered, used, seen, etc." Some of the well-known definitions of accessibility include "the potential of opportunities for interactions" (Hansen, 1959) and "the ease with which any land-use activity can be reached from a location using a particular transport system" (Dalvi and Martin, 1976). Ingram (1971) stated that accessibility may be defined as "the inherent characteristic (or advantage) of a place with respect to overcoming some form of spatially operating source of friction (for example, time and/ or distance)".

\subsection{Accessibility Measures: Certain Approach}

There are several constraints which govern human behaviour and combine to circumscribe the activities in which an individual can participate (Odoki et al., 2001). The following categories of constraints are considered to be relevant 
in determining accessibility (Odoki et al., 2001; Pred, 1977).

a. Transportation constraints: that circumstances behavior by limiting the distances individuals can travel within a particular time span using available transportation system (mode, routing, timing cost, etc.).

b. Temporal constraints: that determines when, and how long an individual must join other individuals (or objects) in order to participate in production, consumption, social and other miscellaneous activities. Generally temporal constraints are a subset of coupling constraints.

c. Spatial constraints: that determines the availability of activities within geographical areas and the locations of specific activities in which individuals participate.

d. Economic, social and cultural aspects: that determines who has or has no access to specific activities at specific times as a result of cultural rules, laws, income levels, gender and social relationships.

e. Coupling constraints: that fix individuals at a point in space for a period of time.

Al Mamun and Lownes (2011) have considered three primary components accessibility viz. (1) trip coverage - travelers would consider public transit accessible when it is available to and from their trip origins/ destinations, (2) spatial coverage - travelers would consider public transit accessible when it is within reasonable physical proximity to their home/destination, and (3) temporal coverage - a service is accessible when service is available at times that one wants to travel. Spatial accessibility i.e. walking distance and walking time is only considered for the present research work.

\subsection{Measuring Spatial Transit Accessibility}

Many factors contribute to transit accessibility, including reasonable proximity from the origin and the destination to the service; safe, pleasant, and comfortable walking pathways to transit facilities; and acceptable parking facilities for cars or bicycles, etc. In public transit planning, access to the service and accessibility provided by the service are two very important issues (Murray et al., 1998). Of the many factors, walking distance to transit facilities is recognized as an important determinant of transit use. A quarter mile, approximately $400 \mathrm{~m}$, is the commonly accepted distance for a people willing to walk to use transit (Demetsky and Lin, 1982). Cervero (2001) found that proximity to a rail station was a much stronger determinant of transit use than land-use mix or quality of the walking environment. Levinson and Brown-West (1984) indicated in their study those transit uses sharply drop after the first 0.06 mile, and diminish beyond 0.36 mile. Zhao et al. (2003) found that transit use deteriorates exponentially with walking distance to transit stops. A decay function was developed to reflect the deteriorating trend in transit use with respect to walk distance. So, increasing suitable access to transit systems is seen as a means of attracting more people to the transit system.

\subsection{GIS Buffering Approach}

Stop access coverage has been estimated using a circular buffer analysis with a radius of the access threshold around the transit stop in order to identify its coverage area (Foda and Osman, 2010). GIS has a long contributing history to location science (Murray, 2010). By means of network 
analysis, GIS facilitates the modeling of distance and delineating service areas (Gutiérrez and García-Palomares, 2008). Also, GIS can help identify which segments of the population remain underserved once transportation infrastructure has been modified.

The proximity to stops must be interpreted creatively, which is possible using the powerful GIS network analysis functions (Foda and Osman, 2010). Salvo and Sabatini (2005) suggested a more spatial approach for identifying optimal stop locations. They proposed a methodology to assess public transportation access coverage in urban areas using a geographical information system.
From this brief review, we can see that, using spatial accessibility measures, it is possible to estimate the transit accessibility index values on the basis of home interview data and as well on GIS base to develop "Accessibility Catchments" through buffering process for different accessibility scales of radiuses.

\section{Database Description}

The West zone of Surat city which is located on the right bank of River Tapti has been selected as study area as belongs to a fast growing residential sector in Gujarat state, India. As per the Census 2011, the population of Surat is 4,462,002 while West zone of that city population is $4,24,986$.

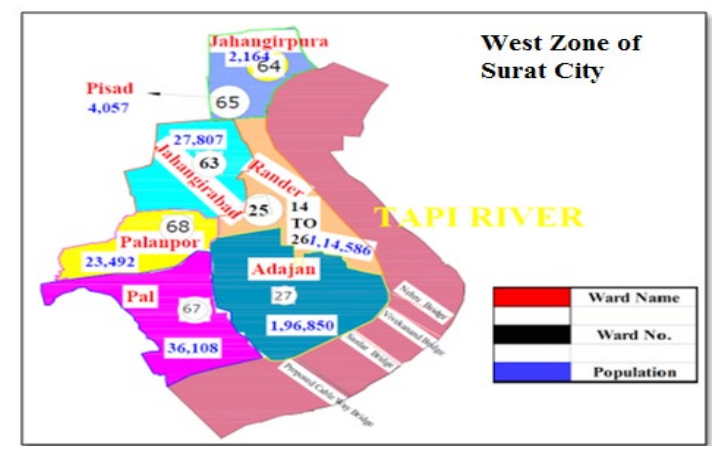

Fig. 1.

Study Area Layout

The field data for the present study was collected by conducting the home interview survey using appropriate questionnaire format prepared based on the standard literatures. The residences were visited by the well trained persons to collect the data from each member of household. Nearly 387 samples are collected from the households of the study area. Questions were explained to respondents in simple, not so technical words, for easy understanding. The survey form contains the socioeconomic characteristics (i.e. household size, family income, age distribution, occupation etc.) and travel information, City Bus Transit Studies and Transit preference data (i.e. preferable distance).

\section{Study Analysis and Discussion}

\subsection{Socioeconomic Analysis}

The socio economic profile has been obtained from Home Interview Survey 
(HIS) covering all types of Income Groups, Family size, Occupation, Residential types and Vehicle ownership in West Zone of Surat City, Gujarat, India. The HIS questionnaire includes LIG, LMIG, HMIG and HHIG where $\mathrm{L}, \mathrm{M}, \mathrm{H}$ tends for Lower, Middle and Higher income levels. Nearly $70 \%$ of the households belong to middle income category, $20 \%$ for higher category and LIG is probably lower sample size. The occupation pattern are divided in four category viz. Govt. Service (15\%), Private Service (58\%), Self Employed (26\%) and Retired Person (1\%). From the female respondents it is found that nearly $77 \%$ are housewives. The data analysis is provided an average family size of 4.48 of the study area. The family activity structure is divided into three categories viz. working member (35\%), education member (27\%) and non employed member (38\%). It is clear from the analysis that maximum vehicle ownership is of $65 \%$ with two wheelers, 18 $20 \%$ with four wheelers, cycling is nearly of 10 to $15 \%$. Ownership value per family bases is $0.46,1.6,0.35$ for cars, $2 \mathrm{~W}$, and bicycle respectively. The residential analysis for the four categories of bungalows (21\%), row house (23\%), apartment (37\%), Tenements (19\%) have been obtained from the study area.

\subsection{Development of Transit Accessibility Index (TAI)}

\subsubsection{Transit Distance Accessibility: Measurements}

\section{- Background}

Walking distance to reach public transport terminals is the most important factor to indicate public transport accessibility (Wibowo and Olszewski, 2005). Most of public transport studies assumed that walking as an access mode occurred up to 400 to 800 meters of walking distance or 10 to 15 minutes of walking time (Halden et al., 2000; Mitchell and Stokes, 1982; O'Sullivan et al., 2000; Pikora et al., 2001; Stringham, 1982; Wibowo and Olszewski, 2005). Here walking distance/time to reach the bus station becomes significant parameter in decision making process on part of public transit users. The acceptable walking distances varies from person to person depending upon his trip purpose, age, and gender. Eventually the bus route network in general and bus route and bus stops in the area and their vicinity matters in quantifying the accessibility. Both macro level (West zone whole) and micro level (Five subzones of West zone (i.e. Adajan, Palanpur, Rander, Jahangirabad and Jahangirpura) public transit studies are important from transit planning, operation and management point of view with reference to transit service operators. The transit accessibility for males and females are considered for this study majorly. Transit accessibility for the children is not included in the above analysis because their movements are based with reference to educational tour.

\section{- Walking Distance: Measurements}

For macro level, it is observed that $54.39 \%$ males indicated present walking distance $350 \mathrm{~m}$ whereas $18.49 \%$ is of females who accept $350 \mathrm{~m}$ as their walking distance. Very few persons are accepting more than $450 \mathrm{~m}$ walking distance. Higher walking distances are accepted only by 10 to $15 \%$ people. For micro level, all the five subzones of the study zones are considered for transit accessibility analysis with accessibility distance of $250 \mathrm{~m}$ to $800 \mathrm{~m}$ for both males and females. Here nearly 72 to $75 \%$ are accepting up to $350 \mathrm{~m}$ of walking distance and female desire to have 
lesser walking distance compare to the males. Except Adajan area nobody wants $500 \mathrm{~m}$ or more of walking distance.

\section{- Walking Time: Measurements}

Nearly 400 persons were interviewed to mention their timing to the nearest bus stop across the bus route and noted walking times. Walking time is segregated in five slots 6-25+ minutes and plus for both males and females. For macro level, the females are accepting 6 minutes or less in more numbers as compare to males. For, micro level observation, higher percentage is observed between 10 and 6 minutes walking time and again females have shown lesser walking time compared to males. Nobody wants to prefer walking time of 15 minutes.

\subsection{Transit Preference Analysis}

Transit riders are interviewed to mention their acceptable walking distance to the bus stops. For macro level observation, nearly $58 \%$ of persons expressed their desired walking distance as less than $200 \mathrm{~m}$ and $53 \%$ preferred walking time of less than 6 minutes. Higher walking distances were expressed by $17 \%$. Nobody wishes to have more than 10 minutes of walking time. It amounts to nearly $400 \mathrm{~m}$ of walking distances. For macro level observation, nearly $75-80 \%$ prefers the accessibility of $350 \mathrm{~m}$ or below. Again $50-60 \%$ prefer $250 \mathrm{~m}$ and below. The distance acceptable above 550 is almost nil. Majority in all the areas are preferring $85-90 \%$ less than 10 minutes and $50 \%$ less than 6 minutes. Here also the people in Adajan have indicated bus stops to be within 6 minutes walk.

\section{Modeling Transit Accessibility}

\subsection{Development of Accessibility Index Values}

It is required to bring the walking distance and walking time in certain modules for relative comparison so that one can consider the level of services status. In view of this an attempt has been made as to develop Accessibility Index value with reference to both walking distance accessibility and walking time accessibility. The Transit Walking Distance Accessibility Index (TAIWD) is defined as the inverse of walking distance $(\mathrm{km})$. Similarly the concept of Transit Walking Time Accessibility Index (TAI-WT) has been introduced in the present study as inverse of walking time (hr). Accordingly the index values of distance and time base accessibilities are calculated and mentioned below in Tables 1 and 2 . Here the accessibility walking distance values of $<200,250,330,450,500$ and $>1000$ metres converted into index values of 5, 4, 3, 2 and 1 respectively. Similarly is the case for walking time values. Higher the index value better is the transit accessibility.

Table 1

Walking Distance Index Values Scaling

\begin{tabular}{|l|l|l|l|l|l|}
\hline Walking Distance (m) & $<\mathbf{2 0 0}$ & $\mathbf{2 5 0}$ & $\mathbf{3 3 3}$ & $\mathbf{5 0 0}$ & $\mathbf{1 0 0 0}$ \\
\hline WD Index & 5 & 4 & $3^{*}$ & 2 & 1 \\
\hline${ }^{*}(1000 / 333)=3$ &
\end{tabular}


Table 2

Walking Time Index Values Scaling

\begin{tabular}{|l|l|l|l|l|l|}
\hline Walking Time (Min.) & $\mathbf{4}$ & $\mathbf{5}$ & $\mathbf{7}$ & $\mathbf{1 0}$ & $>\mathbf{2 0}$ \\
\hline WT Index & 5 & $4^{*}$ & 3 & 2 & 1 \\
\hline${ }^{*}(20 / 5)=4$ &
\end{tabular}

\subsection{Determining Index Values}

With reference to the Walking Distance Accessibility Index and Walking Time Accessibility Index assigned in the above tables, the average index values for this category are carried out with reference to the numbers of corresponding members such as males and females are worked out and presented in Table 3.

Table 3

Observed Transit Accessibility Index Values - Walking Distance (TAI-WD)* and Walking Time (TAI-WT)*

\begin{tabular}{|c|c|c|c|c|c|c|c|}
\hline \multicolumn{4}{|c|}{ Walking Distance Index } & \multicolumn{4}{|c|}{ Walking Time Index } \\
\hline \multicolumn{2}{|l|}{ Members } & \multirow{2}{*}{$\begin{array}{r}\text { Males } \\
3.57^{*}\end{array}$} & \multirow{2}{*}{$\frac{\text { Females }}{3.83^{*}}$} & \multicolumn{2}{|l|}{ Members } & \multirow{2}{*}{$\frac{\text { Males }}{3.89^{*}}$} & \multirow{2}{*}{$\frac{\text { Females }}{3.83^{*}}$} \\
\hline \multirow{6}{*}{ TAI-WD } & Adajan & & & \multirow{6}{*}{ TAI-WT } & Adajan & & \\
\hline & Palanpur & 4.25 & 5 & & Palanpur & 4.5 & 4.05 \\
\hline & Rander & 4.25 & 4.67 & & Rander & 4.08 & 4.46 \\
\hline & Jahangirpura & 4.09 & 4.09 & & Jahangirpura & 4 & 4.3 \\
\hline & Jahangirabad & 4.29 & 4.17 & & Jahangirabad & 4.14 & 4.38 \\
\hline & West Zone & 4.09 & 4.35 & & West Zone & 4.12 & 4.2 \\
\hline
\end{tabular}

Certain numbers of transit riders quoted lower walking distance and lower waiting time keeping accessibility to transit routes rather bus stops. In such cases $150 \mathrm{~m}$ is added as additional distance from the approach to the transit route to the bus stop when reasons where asked, answer was once they reach the transit route they have option of getting Auto rickshaw or city bus service i.e. if they do not get auto they can walk to the bus stop. Higher index values have been observed for the females. In case of males, the index values have been their work trips therefore they have to walk up to the bus stop. In case of females for non worked trips which are of short trip length did not mind to make use of shared autos and female members who have walking distance of $250 \mathrm{~m}$ or less only obtain the bus transit. Due to this reason their indices values are higher. The accessibility indexes at macro level of West Zone are given in the last rows for the both cases.

\section{GIS Software Base}

\subsection{General}

GIS is the Geographic Information System which manipulates the spatial areas and provides lot of information pertaining to the study on graphical platform. ESRI's ArcGIS 9.3 was used to develop walking accessibility circles and buffering analysis. Accessibility measurement in metres can be made provided the details of the residential buildings along the bus route near the bus stop are available. GIS provides such needed 
information in detail and also location of bus route network and bus stops.

\subsection{GIS Application on Transit Accessibility}

\subsubsection{Identification of Bus Stops}

For computation of accessibility on GIS platform three major bus stops namely
Adajan Patiya, Gujarat Gas Circle, Rushabh Tower from Adajan area is selected on three bus route no 112,414 and 119 respectively for the study purpose.

This is a typical case analysis to realize the GIS application as a tool of transit accessibility measurement as shown in the Fig. 2. As such the map belongs to AutoCAD file.

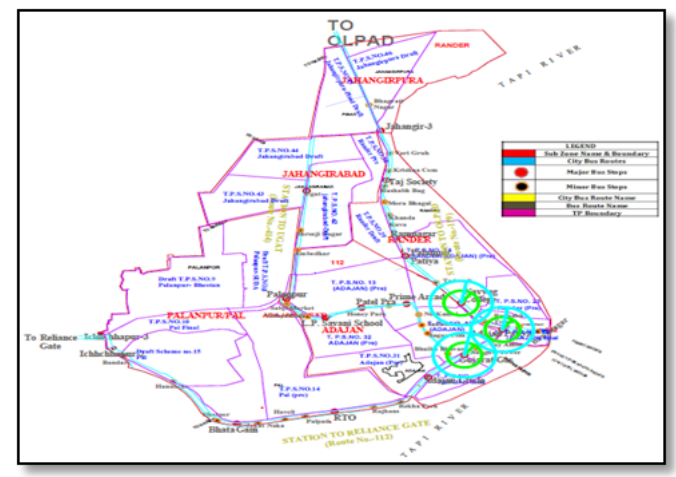

Fig. 2.

Typical Case Bus Stops in Study Area

\subsubsection{Development of Accessibility Catchments}

The likely settlements are residential buildings covered by transit accessibility scaled to $250 \mathrm{~m}, 350 \mathrm{~m}, 450 \mathrm{~m}, 550 \mathrm{~m}$ and $800 \mathrm{~m}$ from the bus stops nearby can be considered as a catchment area for particular scale. The lists of apartments covered by circles generated with accessibility values as radius and bus stop as center. Here accessibility is measured as centroid distance for simplification. In reality, the transit accessibility would vary by $10-20 \%$ more than the radial distance subjected to configuration of residential streets. The catchment area increases with radial distance. Fig. 3 indicates circles of transit accessibility from $250 \mathrm{~m}-800 \mathrm{~m}$ in different colors, where green circle and nevi blue circle provide extreme range of accessibilities. Circles are drawn on major bus stops on existing bus routes of the study areas. 

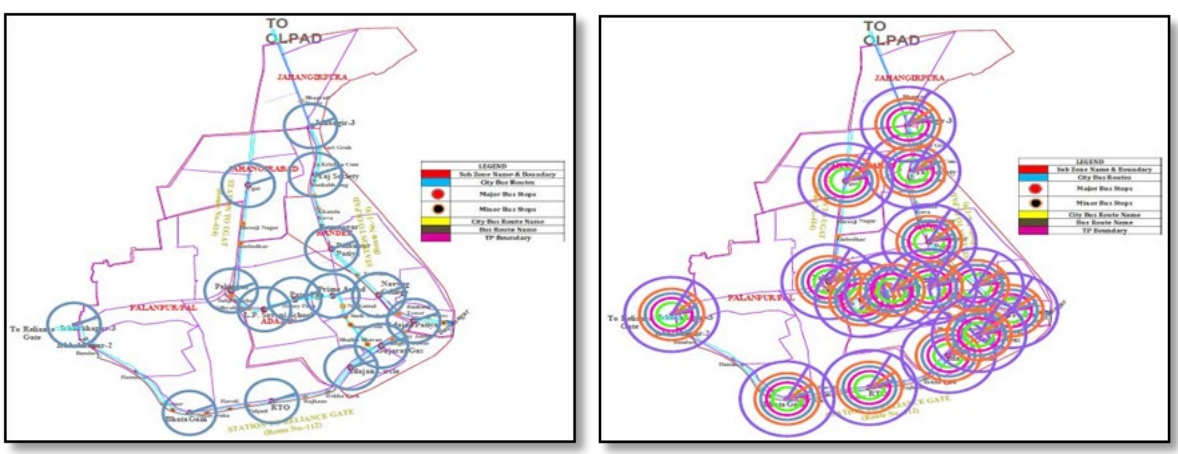

Fig. 3.

Accessibility Catchment Areas for $350 \mathrm{~m}$ and all with Combine

\subsubsection{GIS Buffering and Impact}

The process of accessibility circular catchment areas on the map on GIS base is termed as

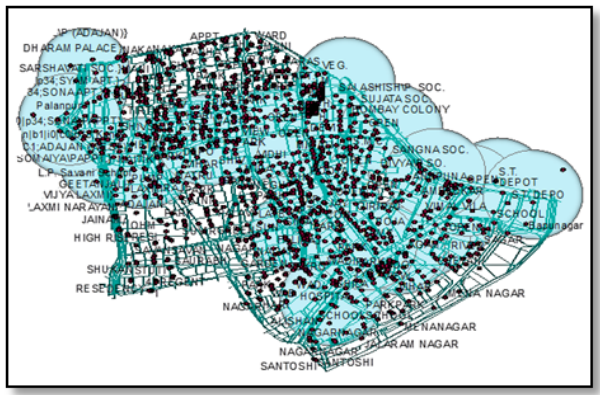

buffering. When the area increases from accessibility $250 \mathrm{~m}$ to $450 \mathrm{~m}$, the buffering results in overlapping of the area. A buffered map in GIS on Adajan area is shown in Fig. 4.

Fig. 4.

Accessibility Catchment Areas Using GIS - 350m and 450m

\section{Proposed LOS of Transit Accessibilities}

Proposed LOS (Level of Service) for the spatial accessibilities in terms of walking distance and time are shown in Table 4.

Table 4

Proposed LOS of TAI-WD

\begin{tabular}{|l|l|l|l|l|l|l|}
\hline LOS & A & B & C & D & E & F \\
\hline TAI-WD/WT & $\mathbf{5}$ & $\mathbf{4}$ & $\mathbf{3}$ & $\mathbf{2}$ & $\mathbf{1}$ & $\mathbf{0}$ \\
\hline Distance (m) & $<200$ & 250 & 333 & 500 & 1000 & $>1200$ \\
\hline Time (Min.) & 4 & 5 & 7 & 10 & 20 & $>20$ \\
\hline
\end{tabular}


Here the value A shows the highest level of service index 5 with the distance of $<200 \mathrm{~m}$ while $\mathrm{F}$ shows the poor LOS index 0 as distance of $>1200 \mathrm{~m}$. If the values is in between $A$ and $B$ than it is labeled as $A B$. If the indexes values are worked out are as 4.5 and 2.8 , the level of services would be AB and DE. Same as that for walking time A shows the highest level of service with the time 4 minutes while 0 index shows for $>20$ minutes walking time.

\section{Summary and Results}

- TAI are developed for both walking distance and walking time and are defined as Spatial Transit Accessibility Index (STAI) in range of 0 to 5 . Higher the index minimum the walking distance or walking time.

- Index values in case of walking distance has highest value of 5, it means walking distance is 200 and less than $200 \mathrm{~m}$ and if index value is zero it is considered as worst if walking distances should be more than $1 \mathrm{~km}$.

- $\quad$ STAI would be 5 for waking time of 6 and less than 6 minutes and is considered best. If walking time is more than $30 \mathrm{~min}$ than it is worst.

- GIS software assists to build up the catchment areas through buffering approach.

- Buffer circles for $250 \mathrm{~m}, 350 \mathrm{~m}, 450 \mathrm{~m}$, $550 \mathrm{~m}$ and $800 \mathrm{~m}$ are developed through GIS platform to establish accessibility catchment areas.

- Overlapping areas by the intersection of the buffer circles reflect the bus stop choices for the riders and here logit discrete choice model can be employed in decision process.

- Six levels are assigned to note the Public Transit Accessibility Levels from A to $\mathrm{F}$ as indicating $\mathrm{A}$ as the best levels and $\mathrm{F}$ as the worst levels of PTAI.

\section{Conclusion}

Urbanization eventually builds up the pressure on transportation system for its infrastructure to meet the increasing transport demand. Main priorities are concerned with public transit system, so that system can become economically viable and sustainable. Transit accessibility plays a vital role in strategic planning of public transportation system. The aim of the research paper analyzed in this paper is to understand the overall walking accessibilities of urbanized Indian cities. A case study was presented by collected data from home interview survey has found out the spatial accessibility level of service of West Zone of Surat city.

The Transit Accessibility Index (TAI) developed in this study shows that for both walking distance and walking time index are defined as Spatial Transit Accessibility Index (STAI) in the range of 0 to 5 and higher the index minimum the walking distance or walking time. These index values in case of walking distance has highest value of 5 , it means walking distance is 200 and less than $200 \mathrm{~m}$ and if index value is zero it is considered as worst if walking distances should be more than $1 \mathrm{~km}$. STAI would be 5 for waking time of 6 and less than 6 minutes and is considered best. If walking time is more than $30 \mathrm{~min}$ than it is worst.

The results shows that the macro level walking distance accessibility for both male and female are highest as 4.67 for Rander area while 4.09 and 4.35 is as average for West Zone whole at macro level. Same as for walking time, the Palanpur area have highest value for both male and female are 4.5 and 4.05 and 4.12 and 4.20 for West Zone whole. These statistical figures show that the present status of walking distances/time accessibility for females are higher in subzones viz. Adajan, 
Palanpur and Rander in comparison to other to subzones which shows that females are more users of public transport in these areas.

Transit preference analysis shows that the majority respondents in all the areas are preferring $85-90 \%$ less than 10 minutes and $50 \%$ less than 6 minutes. The people of Adajan area have indicated bus stops to be within 6 minutes walk. This shows that their preference regarding the public transit is less because of poor level of the service in the study area. The proposed LOS for macro level observation for walking distance is $\mathrm{C}$ and walking time is $\mathrm{D}$ which shows the poor level of accessibility of the study area. The respondents' preferable choice for both level observations shows the LOS of A which is presently not available into the study area. GIS application through buffer analysis shows the overlapping areas at the bus stops by the intersection of the buffer circles which reflect the bus stop choices for the riders of the transit users. So, this paper finally assists to find out the spatial accessibility of the urbanized metropolitan cities in GIS base.

\section{References}

Al Mamun, M.S.; Lownes, N.E. 2011. A composite index of public transit accessibility, Journal of Public Transportation, 14(2): 69-87.

Arentze, T.A.; Borgers, A.W.; Timmermans, H.J. 1994. Multistop-based measurements of accessibility in a GTS environment, International Journal of Geographical Information Systems, 8(4): 343-356.

Cervero, R. 2001. Walk-and-ride: factors influencing pedestrian access to transit, Journal of Public Transportation, 7(3): 1-23.

Dalvi, M.Q.; Martin, K. 1976. The measurement of accessibility: some preliminary results, Transportation, 5(1): 17-42.
Demetsky, M.J.; Lin, B.B.-M. 1982. Bus stop location and design, Journal of Transportation Engineering, 108(TE4): 313-327.

Dong, X.; Ben-Akiva, M.E.; Bowman, J.L.; Walker, J.L. 2006. Moving from trip-based to activity-based measures of accessibility, Transportation Research Part A: Policy and Practice, 40(2): 163-180.

Foda, M.A.; Osman, A.O. 2010. Using GIS for measuring transit stop accessibility considering actual pedestrian road network, Journal of Public Transportation, 13(4): 23-40.

Geertman, S.C.; Ritsema Van Eck, J.R. 1995. GIS and models of accessibility potential: an application in planning, International Journal of Geographical Information Systems, 9(1): 67-80.

Gutiérrez, J.; García-Palomares, J.C. 2008. Distancemeasure impacts on the calculation of transport service areas using GIS, Environment and Planning B: Planning and Design, 35(3): 480-503.

Gutiérrez, J.; Monzon, A.; Piñero, J.M. 1998. Accessibility, network efficiency, and transport infrastructure planning, Environment and Planning A, 30(8): 1337-1350.

Halden, D.; McGuigan, D.; Nisbet, A.; McKinnon, A. 2000. Accessibility: Review of measuring techniques and their application.

Hansen, W.G. 1959. How accessibility shapes land use, Journal of the American Institute of Planners, 25(2): 73-76.

Ingram, D.R. 1971. The concept of accessibility: a search for an operational form, Regional Studies, 5(2): 101-107.

Juliao, R.P. 1999. Measuring accessibility using GIS. In Proceedings of GeoComputation99, Fourth International Conference on Geo Computation, Fredericksburg, USA, 25-28.

Kwan, M.P. 1998. Space time and integral measures of individual accessibility: a comparative analysis using a point based framework, Geographical Analysis, 30(3): 191-216. 
Levinson, H.S.; Brown-West, O. 1984. Estimating bus ridership, Transportation Research Record, 994: 8-12.

Levinson, H.S. 1992. Urban Mass Transit Systems. In Edwards, J.D. (ed.), Transportation Planning Handbook. Prentice Hall, New Jersey.

Loutzenheiser, D. 1997. Pedestrian access to transit: Model of walk trips and their design and urban form determinants around Bay Area Rapid Transit stations, Transportation Research Record, 1604: 40-49.

Mitchell, C.; Stokes, R. 1982. Walking as a Mode of Transport. $24 \mathrm{p}$.

Murray, A.T. 2010. Advances in location modeling: GIS linkages and contributions, Journal of Geographical Systems, 12(3): 335-354.

Murray, A.T.; Davis, R.; Stimson, R.J.; Ferreira, L. 1998. Public transportation access, Transportation Research Part D: Transport and Environment, 3(5): 319-328.

O’Sullivan, D.; Morrison, A.; Shearer, J. 2000. Using desktop GIS for the investigation of accessibility by public transport: an isochrone approach, International Journal of Geographical Information Science, 14(1): 85-104.

O’Sullivan, S.; Morrall, J. 1996. Walking distances to and from light-rail transit stations, Transportation Research Record, 1538: 19-26.

Odoki, J.B.; Kerali, H.R.; Santorini, F. 2001. An integrated model for quantifying accessibility-benefits in developing countries, Transportation Research Part A: Policy and Practice, 35(7): 601-623.

Pikora, T.; Giles-Corti, B.; Donovan, R. 2001. How far will people walk to facilities in their local neighbourhoods?. In Proceedings of Australia: Walking the 21 st Century, International Conference, Perth, Western Australia, Vol 3.
Polzin, S.; Chu, X.; Rey, J. 2000. Density and captivity in public transit success: observations from the 1995 nationwide personal transportation study, Transportation Research Record, 1735: 10-18.

Pred, A. 1977. The choreography of existence: comments on Hägerstrand's time-geography and its usefulness, Economic Geography, 53(2): 207-221.

Rudnicki, A. 1999. Equivalent travel time of passengers as a synthetic performance measure in urban public transport. In Proceedings from the 2 nd KFB-Research Conference on Urban Transport Systems, 174-183.

Salvo, G.; Sabatini, S. 2005. A GIS approach to evaluate bus stop accessibility. In Proceedings of Advanced OR and AI Methods in Transportation, 284-289.

Shen, Q. 1998. Location characteristics of inner-city neighborhoods and employment accessibility of lowwage workers, Environment and Planning B: Planning and Design, 25(3): 345-365.

Stringham, M. 1982. Travel behavior associated with land uses adjacent to rapid transit stations, ITE Journal, 52(4): 18-22.

Van Eck, J.R.; De Jong, T. 1999. Accessibility analysis and spatial competition effects in the context of GIS-supported service location planning, Computers, Environment and Urban Systems, 23(2): 75-89.

Wibowo, S.S.; Olszewski, P. 2005. Modeling walking accessibility to public transport terminals: Case study of Singapore mass rapid transit, Journal of the Eastern Asia Society for Transportation Studies, 6: 147-156.

Zhao, F.; Chow, L.-F.; Li, M.-T.; Ubaka, I.; Gan, A. 2003. Forecasting transit walk accessibility: regression model alternative to buffer method, Transportation Research Record, 1835: 34-41. 